\title{
The procedures to be followed to provide safe legal abortion services to women pregnant after rape
}

\author{
Anibal Faúndes ${ }^{1,2 *}$ \\ ${ }^{1}$ Center for Research in Human Reproduction of Campinas (CEMICAMP), Campinas, Brazil \\ ${ }^{2}$ Department of Obstetrics and Gynaecology, Faculty of Medicine, State University of Campinas, Campinas, Brazil
}

\begin{abstract}
Until 1996, there were only four public hospitals in Brazil, which occasionally provided legal abortion services to women victims of rape. In November of that year a Forum was held to discuss ways to make legal abortion, particularly after rape, accessible to Brazilian women. Among other stakeholders, Professor of Obstetrics and Gynecology of Brazilian Universities were invited, with the intention to stimulate them to provide legal abortion services at their respective University hospitals. The Forums were repeated every year to review the progress and the proposed procedures, based in the experience being gained along the years, which allowed to make clearer recommendation with reference to the procedures to be followed to provide safe legal abortion services after rape. Those procedures are described in the understanding that they should be applicable to the many other countries in which abortion is allowed after rape, but the law is almost never applied.
\end{abstract}

\section{Introduction}

Until 1996, there were only four public hospitals in Brazil, which occasionally provided legal abortion services to women victims of rape. The Penal Code of 1940 allowed the termination of pregnancy if it was the only means to save the woman's life and in case the pregnancy was the result of rape. No regulations on how to apply the law had never been produced and the result was that the law was almost never applied.

Females mayors of Rio de Janeiro and São Paulo, the two largest cities in the country, had established legal abortion services for rape victims who get pregnant in one municipal hospitals of each of these two cities. One University hospital in the city of Campinas, Sao Paulo State, and another in the city of Sao Paulo, also provided these services, in rare occasions, until 1996 [1].

This situation was in contrast with a high incidence of sexual violence, both in the public environment and within the families [2], which many times resulted in absolutely unwanted pregnancies which almost always ended in an unsafe, clandestine abortion, more unsafe, the lower the women's economic conditions. The observation of that situation led the Center for Research on Human Reproduction of Campinas (CEMICAMP) together with the Department of Obstetrics and Gynecology of the State University of Campinas (UNICAMP) to organize an Inter-professional Forum for the Implementation of Abortion according to the Law, in November of 1996. Representative from the four hospitals that provided legal abortion services were invited, as well as representative from the Judicial system, special women' centered police department, forensic medicine, female rights oriented NGOs, Federal Council of Medicine, Ministry of Health, Brazilian Federation of Gynecology and Obstetrics Societies (FEBRASGO) and more important, Full Professors of Obstetrics and Gynecology from several states of Brazil, who had the capacity to install legal abortion services in their respective University Hosp itals. The main outcome of the First Forum was the proposal of the procedures that hospitals should follow when a woman who suffered rape request pregnancy termination [3]. In addition, FEBRASGO created a National
Committee on Sexual Violence and Abortion according to the Law in 1997 and the Ministry of Health launched guidance on the Care for Women and Adolescents who suffer Sexual Violence in 1998.

Such Forums were repeated year after year for many years and new suggestions based in actual experiences were accumulated and allowed to make clearer recommendation with reference to the procedures to be followed to provide safe legal abortion services in Brazil, which should be applicable to the many other countries in which abortion is allowed after rape but the law is almost never applied.

Although the Forums discussed both emergency services after rape and pregnancy termination for those who got pregnant, we describe below only the recommendations produced by the six first Forums in relation to legal termination of pregnancy, with some minimal additions, as for example, by including the use of mifepristone as a medical method for pregnancy termination, although it is not available in Brazil until now (2017).

\section{Material and method}

The report of the first six Forums, which were published each year in the officla journal of FBRASGO, called Femina, were systematically review an analyzed. The basic recommendation that the members of the Forum proposed according to the experience acquired with the installation of services in different hospitals, mainly University Teaching Hospitals, were selected. In some cases, particularly in

Correspondence to: Anibal Faúndes, Center for Research in Human Reproduction of Campinas (CEMICAMP), Campinas, BrazilRua Vital Brasil 200, P.O. Box 6181 Cidade Universitária 13.084-971 Campinas, São Paulo, Brazil, Tel: +55 193289 2856; Fax: +55 193289 2440; E-mail: afaundes@unicamp.br

Key words: legal abortion, rape, hospital procedures, psychological care, method of abortion

Received: January 18, 2018; Accepted: February 05, 2018; Published: February 08,2018 
relation to the methods of abortion, such recommendation were updated according to the current knowledge and based on the World Health Organization guidelines.

\section{Results}

\section{How to start the process of installation of services to provide legal pregnancy termination after rape.}

This process cannot start by a vertical decision taken by the hospital authorities, but it should broadly have discussed before deciding how the procedure will be organized. This should be an internal discussion within the hospital but including all the professionals who potentially may be involved in any aspect of the care of women requesting legal termination of pregnancy. In case the hospital has legal assistance, it should also be included in these discussions.

Only in a second stage, when the procedure to be followed have been internally established, other partners can be informed on how the legal abortion services will be carried out. University human rights and women's right advocates, representative of the police, forensic medicine, Regional Council of Medicine, judiciary system should be informed, as they can have received request of assistance from pregnant women victims of rape and need to know how to provide orientation on where they can get assistance.

\section{Sensitization and training}

For the purpose of sensitization of all the institution's personnel, activities such as educational videos, dramatization, clarification meetings and debates are proposed. Within that context, the contents such as information that ensure the legality of pregnancy termination in specific conditions and clarifying that the number of abortion will not be increase, but the only effect would be that women who have the right to a safe pregnancy termination according to the law, will not need to recur to clandestine unsafe abortion, but will receive the appropriate care that they have the right to receive.

All this information should be provided to all the institution's personnel, and not only those directly implicated in the provision of services.

The members of the staff who will be directly involved in providing safe abortion care should be specifically trained on how to deal with women who request termination of pregnancy after rape. Physicians should be specifically trained in all the techniques recommended for the termination of pregnancy by the World Health Organization and the International Federation of Gynecologists and Obstetricians (FIGO).

\section{Which hospitals should be involved}

Most of the hospitals that provide emergency care to women who suffer sexual violence, also include safe abortion services for those who become pregnant and request termination. Members of the Forum accepted that some these hospitals do not provide abortion services if they can refer these cases to another hospital within easy access.

On the other hand, the Forum recommends that every University teaching hospital is involved in the provision of legal termination of pregnancy in order to train the new generation of physician and other health professional in an environment where these services are seen as part of their duty of protect the health and lives of women, replacing clandestine unsafe abortion for safe abortion for women who comply with the law [4].

\section{Services these hospitals should be prepared to provide at} admission

a) Psychological care of women who get pregnant after rape and request termination: Every woman who goes through the process of requesting and getting a legal termination of pregnancy needs psychological evaluation and support.

\section{The psychological evaluation should include at least the following:}

- Her feeing's after realizing that is pregnant as result of a sexual violence: rejection, guilty, ambibalance, acceptance;

- Her religious and moral principles which may interfere in her decision;

- Fantasies and myths related to pregnancy and abortion.

After evaluation the woman should receive psychological care during the period in hospital or during pregnancy is she chooses to carry on the pregnancy to term. In many cases, her husband and family may also require psychological support [5].

b) Counseling about rights and alternatives: The woman should receive complete information about her rights according to Brazilian laws and regulations, and about the alternatives of accepting to continue the pregnancy up to term or terminating it the sooner possible. In cases where the woman express her wish of carrying on the pregnancy to term, the possibility of giving the newborn for adoption or keeping the baby, should be discussed.

The health professional in charge should not, in any circumstance, express his her personal opinion, in order to guide the women to a given alternative, but inform her about all the possible choices, motivating her to thinks about her reproductive rights, her health and her personal conditions, for a well-informed, conscientious and voluntary decision. The role of health service is to present the options, but the final decision is exclusive of the affected woman. In case she decides to give the newborn for adoption, she should be fully informed that she has to irrevocably renounce to his rights as a mother. The health service should get in touch with the appropriate organization in charge of the adoption procedures.

\section{Requirement to accept the occurrence of rape}

Documents needed to ensure the legality of the procedure: Originally a police statement that the woman had denounced to have been raped in given circumstances was required, but after documenting that many women were frequently discriminated at the police stations and accused of provoking the violence, that condition was replaced by a written declaration of the circumstances of the rape, signed by the woman (or her legal representative if a minor) and kept attached to the clinical records.

A separate written request for pregnancy termination is also required. In the case of a minor, it should be signed by her legal representative, but if the minor expresses her desire to keep the pregnancy, the desire of the pregnant minor should be respected.

The police statement is no longer legally required, but is recommended in order to prosecute the aggressor, but respecting the woman's right to decide if she wants to denounce the aggression or not. This police statement should also be attached to the clinical record.

Report of the Forensic Medicine Institute. Such report of the forensic examination of the victim is not a requirement to carry out the pregnancy termination but facilitate the investigation in case the 
woman wants to denounce the aggression. It should also be kept with the clinical record.

A judicial order or authorization of the pregnancy termination is not required and should not be requested.

Although the word of the women should be trusted, the Forum recommend that every woman who request pregnancy termination after a rape, which she declares to have suffered, should be informed of the possibility of being accused of the crime of "false testimony", in case her declaration of rape proved to be incorrect. If with her declaration she induces the health service to carry out the abortion, she will become responsible of the crime of inducing an abortion [6].

\section{Criteria's for the approval of the legal pregnancy termination}

a) Gestational age: In some hospitals the maximum gestational age to accept a request of pregnancy termination after rape is 12 weeks, but it is know that sometime, particularly adolescents do not report their condition until later, and in many occasions it takes time since they look for care and they reach to a hospital that provides safe legal abortion services.

For that reason requests after 12 weeks should be considered and analyzed individually. The final decision should be based in the clinical and psychological conditions of each case.

b) Credibility of the story of rape: Although in principle we should trust in the words of the woman, the hospital may reject the request of termination in case there is a significant inconsistency in the story of the aggression. In addition, it can also be rejected if there is a sizable difference between the gestational age confirmed by ultrasound and the date of the rape according to the patient.

\section{Flux of the woman within the health institution}

At admission to the hospital, the woman should be referred with preference to a social worker who is assigned to comply that function. If that were not possible she should be referred to another professional, who may be a physician, nurse or psychologist according to the conditions at each institution.

The social worker or the professional assigned by the institution will collect all the information provided by the woman in relation to the agreesion suffered and will registered in detail in writing for the information of the other health workers who will care for that woman in sequence. The other health care worker will not ask again for the same story but may need to ask additional questions related to the services they will deliver. The physician may ask questions on details require for the diagnosis, but without requiring the repetition of the full story of the aggression.

The physician responsible for the initial clinical examination may or may not be the same who perform the pregnancy termination. The time going from admission until the pregnancy termination should be the shorter considering the emotional conditions of the patient. In no case that time lapse will be longer than one week.

\section{Method for pregnancy termination}

Ideally the woman should have the right to choose whether the method use is medial or surgical, but that will depend of the capacity of each institution and the training of the professional working on it.

\section{Pregnancy termination up to 12 weeks of gestational age}

Pregnancy termination during the first trimester can be carried out using surgical or medical methods. The surgical method recommended by the World Health Organization and FIGO vacuum aspiration, manual or electrical. Both organizations recommend to abandon dilatation and curettage for intrauterine aspiration because the latter is equally effective, it causes less ill effects and do not require general anesthesia, neither the use of a surgical theatre.

Abortions using aspiration or medications are highly effective and require less training of the provider, who doesn't need to be a physician, as it can be provided by nurses with equal effectiveness and patient's satisfaction [7].

The procedure should be initiated with the administration of oral mifepristone $200 \mathrm{mg}$, followed by the administration of misoprostol $800 \mathrm{mcg}$ by the vaginal, buccal or sublingual routes. The interval between the administration of mifepristone and misoprostol should be of 1 to 2 days (24-48 horas) with gestational age up to 9 weeks, and of 36 to 48 between 10 and 12 weeks.

Up to 9 weeks misoprostol can be administered by the woman herself, meaning that she doesn't need to return to the clinic to have the misoprostol [8]. Between 10 and 12 weeks the patient should be admitted in a hospital from the first administration of misoprostol followed by $400 \mathrm{mcg}$ of misoprostol every 3 hours, vaginally or sublingually, for a maximum 4 dosages until the uterine evacuation is completed [8].

In case mifepristone is not available, misoprostol alone can be used, in dosages of $800 \mathrm{mcg}$, by the vaginal or sublingual, repeating the same dosage every three hours, for a maximum of three times. In case it doesn't have the expected effect the same scheme can be repeated 24 hours later. The scheme is the same until 12 weeks of gestational age [9].

\section{Method for pregnancy termination with gestational age above 12 weeks}

Administration of $200 \mathrm{mg}$ of oral mifepristone followed 36 to 48 hours later by misoprostol $800 \mathrm{mcg}$ vaginally and then, $400 \mathrm{mcg}$ misoprostol vaginally or sublingual, every 3 hours, for a maximum of 5 dosages, administered with the patient admitted in hospital [8].

If mifepristone is not available, Misoprostol alone can be used in doses of $400 \mathrm{mcg}$, by the vaginal, buccal or sublingual route, every 3 hours until uterine evacuation [9].

The recommended surgical method is Dilatation and Evacuation (D\&E), using aspiration and special forceps [8]. It requires of well trained professional providers with experience in the practice of this procedure. The creviz should be prepare by using osmotic dilatators (laminaria) or the administration of $400 \mathrm{mcg}$ of vaginal misoprostol, $3-4$ hours before or sublingual, $2-3$ hours before the procedure $[8,10]$. If properly trained and experienced providers were not available, medical methods with mifepristone and misosprostol or misoprostol alone should be used instead of D\&E.

The routinely use of antibiotics is recommended when surgical methods are used, but it is not required in case of abortion with medication as the risk of infection is minimal and the same with or without prophylactic antibiotics.

Patients should be advise that they should urgently return to the hospital in case they have heavy or persistent bleeding, if the pain continues after the uterine evacuation or if they have fever. All of these complaints are symptoms of incomplete abortion. 


\section{Follow up after abortion}

Every hospital that provides legal termination of pregnancy should ensure that every women is follow up for as long as they need care. The Forum recommends that follow up care, particularly psychological care, is offered to every women consulting for pregnancy after rape, either if that pregnancy is terminated or not.

Those who continued the pregnancy should receive special antenatal care by professionals who know and understand their circumstances. As we said earlier, the possibility of giving the newborn for adoption should be always offered.

\section{Discussion}

The prevalence of sexual violence is much higher that most people suspect, affecting almost one of every three women sometime during their lives $[11,12]$. If those women were not using and effective contraceptive and were around the fertile days of the cycle, they run a high risk of getting pregnant if they do not use emergency contraception, but even using them around $2 \%$ will get pregnant. In most countries in the world abortion is permitted for women who get pregnant after rape, but in countries with restrictive laws, those conditions in which the law can be applied are rarely recognized and the prevalent concept that abortion is a crime is an insurmountable barrier for women who get pregnant after rape: they almost never get access to safe legal abortion in a public hospital.

When there is the good intention to put the law in practice, obstetricians, gynecologists and policy makers do not know how to put these good intentions into practice. We believe that the experience gained in Brazil can be an important contribution to other countries, which would like to follow the same path.

\section{Conclusions}

Brazil gained a good experience in making legal abortion after rape accessible to women who had suffered sexual assault and get pregnant.
Sharing that experience may be very useful for other countries in similar conditions.

\section{References}

1. Faúndes A, Duarte GA, Osis MJD, Bento SF (1997) "Normas e procedimentos jurídicolegais utilizados para obtenção do aborto legal nos serviços de saúde no Brasil”. Revista Brasileira de Ginecologia e Obstetrícia 19: 171-176.

2. Heise L (1994) Gender-based abuse: The global epidemic. Cad Saúde Pública 10 135-45.

3. Faúndes A, Bedone A, Bastos AF, Pedro Neto AH, Santos CA, et al. (1997) I Fórum Interprofissional para Implementação do Atendimento ao Aborto Previsto na Lei Relatório Final”. Femina 25: 69-78.

4. Faúndes A, Leocádio E, Andalaft-Neto J (2001) V Fórum de atendimento integral à mulher vítima de violência sexual. Relatório Final. Femina 29: 107-112.

5. Faúndes A, Andalaft Neto J, Freitas F (1999) III Forum Interprofissional para Implementação do Atendimento ao Aborto Previsto por Lei. Femina 27: 317-321.

6. Faúndes A, Oliveira G, Andalaft Neto J, Costa Lopez JR (1998) II Forum Interprofissional para Implementação do Atendimento ao Aborto Previsto em Lei. Femina 26: 134-138.

7. Tamang A, Shah IH, Shrestha P, Warriner IK, Wang D, et al. (2017) Comparative satisfaction of receiving medical abortion service from nurses and auxiliary nursemidwives or doctors in Nepal: results of a randomized trial. Reprod Health 14: 176. [Crossref]

8. WHO (2012) Safe abortion: technical and policy guidance for health systems. 2nd Edn, World Health Organization, Human reproduction programme.

9. Morris JL, Winikoff B, Dabash R, Weeks A, Faundes A, et al (2017). FIGO's updated recommendations for misoprostol used alone in gynecology and obstetrics. International Journal of Gynecology \& Obstetrics pp.1-4.

10. Kapp N (2010) Cervical preparation for first trimester surgical abortion. Cochrane Database of Systematic Reviews 2: CD007207.

11. Breiding MJ, Smith SG, Basile KC, Walters ML, Chen J, et al. (2014) Prevalence and characteristics of sexual violence, stalking, and intimate partner violence victimization-national intimate partner and sexual violence survey, United States, 2011. MMWR Surveill Summ 63: 1-18. [Crossref]

12. Dartnall E, Jewkes R (2013) Sexual violence against women: the scope of the problem. Best Pract Res Clin Obstet Gynaecol 27: 3-13.

Copyright: (C2018 Faúndes A. This is an open-access article distributed under the terms of the Creative Commons Attribution License, which permits unrestricted use, distribution, and reproduction in any medium, provided the original author and source are credited. 